\title{
In-Space Propulsion, Logistics Reduction, and Evaluation of Steam Reformer Kinetics: Problems and Prospects
}

\author{
D.A. Jaworske ${ }^{1}$, B.A. Palaszewski ${ }^{2}$, M.J. Kulis ${ }^{3}$, and S.A. Gokoglu ${ }^{4}$ \\ NASA Glenn Research Center, 21000 Brookpark Road, Cleveland, OH 44135
}

\begin{abstract}
Human space missions generate waste materials. A 70-kg crewmember creates a waste stream of $1 \mathrm{~kg}$ per day, and a four-person crew on a deep space habitat for a $400+$ day mission would create over $1600 \mathrm{~kg}$ of waste. Converted into methane, the carbon could be used as a fuel for propulsion or power. The NASA Advanced Exploration Systems (AES) Logistics Reduction and Repurposing (LRR) project is investing in space resource utilization with an emphasis on repurposing logistics materials for useful purposes and has selected steam reforming among many different competitive processes as the preferred method for repurposing organic waste into methane. Already demonstrated at the relevant processing rate of $5.4 \mathrm{~kg}$ of waste per day, high temperature oxygenated steam consumes waste and produces carbon dioxide, carbon monoxide, and hydrogen which can then be converted into methane catalytically. However, the steam reforming process has not been studied in microgravity. Data are critically needed to understand the mechanisms that allow use of steam reforming in a reduced gravity environment. This paper reviews the relevant literature, identifies gravity-dependent mechanisms within the steam gasification process, and describes an innovative experiment to acquire the crucial kinetic information in a small-scale reactor specifically designed to operate within the requirements of a reduced gravity aircraft flight. The experiment will determine if the steam reformer process is mass-transport limited, and if so, what level of forced convection will be needed to obtain performance comparable to that in 1-g.
\end{abstract}

\section{Nomenclature}

$\begin{array}{ll}C & =\text { Celsius } \\ G r & =\text { Grashof number } \\ K & =\text { Kelvin } \\ \mathrm{kg} & =\text { kilogram } \\ \mathrm{m} & =\text { meter } \\ \mathrm{nm} & =\text { nanometer } \\ \mathrm{s} & =\text { second }\end{array}$

\section{Introduction and Background}

$\mathrm{H}$ UMAN space missions generate waste materials. A 70-kg crewmember creates a waste stream of approximately $1 \mathrm{~kg}$ per day, and a four-person crew on a deep space habitat for a $400+$ day mission would create over $1600 \mathrm{~kg}$ of waste. ${ }^{1}$ Converted into methane, the carbon could be used as a fuel for propulsion or power. Waste disposal techniques currently utilized on International Space Station (ISS), a Progress tanker for disposal, are not the solution to waste disposal on a deep space habitat. A recent study indicated routine jettisoning of waste overboard, utilizing an air-lock, would waste significant amounts of gas and contaminate the

\footnotetext{
${ }^{1}$ Physicist, Fluid and Transport Processes Branch, Mail Stop 309-2, AIAA Associate Fellow.

${ }^{2}$ Leader of Advanced Fuels, Combustion Branch, Mail Stop 5-10, AIAA Associate Fellow.

${ }^{3}$ Combustion Engineer, Env. Effects and Coatings Branch, Mail Stop 110-3.

${ }^{4}$ Senior Scientist, Combustion and Reacting Systems Branch, MS 77-5, AIAA Member
} 
vicinity with debris. ${ }^{2}$ For NASA's deep space missions, waste is a potential resource that could be repurposed into fuel for propulsion or power with the added benefit of (re-)generating habitable volume.

In this study, a review of the relevant steam reformer literature is summarized, with emphasis on the identification of gravity-dependent mechanisms within the steam gasification process. An understanding of the problems associated with gravity-dependent mechanisms leads to a discussion on the prospects of utilizing steam reforming in a reduced gravity environment where mass transport limitations play a role. A reduced gravity experiment to acquire the crucial kinetic information in a small-scale reactor specifically designed to fit within the requirements of an aircraft parabolic flight is considered. The experiment will provide answers to whether the steam reformer process can be utilized in microgravity, determining if the steam reformer process is mass transport limited, and if so, what level of forced convection would be needed to obtain performance comparable to that in 1-g. Potential features of the steam reformer are also discussed.

A major departure from previous work is to consider the influence of gravity on the steam gasification process. Though considerable modeling has been reported in the literature, the modeling was designed for terrestrial applications where buoyancy and convection play a role. ${ }^{3-5}$ Previous modeling was for applications such as coal and biomass gasification, often in the absence of added oxygen. Recent work by Pioneer Astronautics, Littleton, CO, utilizing oxygenated steam, suggests that there is a significant reduction in the volume of organics via a multistep process. ${ }^{6}$ Organic volatiles first combine with the oxygen in the steam carrier gas, in essence a combustion process that yields a release of heat in the vicinity of the organics in the reaction chamber. This rapid exothermic reaction preheats additional organics creating what is considered here to be a nascent porous char. As the temperature exceeds $800{ }^{\circ} \mathrm{C}$, steam reacts with the nascent char via the steam gasification reaction and carbon dioxide present from combustion reacts with the nascent char via the Bouduard reaction, equations (1) and (2) respectively. The Water-Gas Shift Reaction (3) is available to maintain equilibrium between carbon monoxide and carbon dioxide. ${ }^{4}$

$$
\begin{gathered}
\mathrm{H}_{2} \mathrm{O}+\mathrm{C} \rightarrow \mathrm{H}_{2}+\mathrm{CO} \\
\mathrm{CO}_{2}+\mathrm{C} \rightarrow 2 \mathrm{CO} \\
\mathrm{H}_{2} \mathrm{O}+\mathrm{CO} \leftarrow \rightarrow \mathrm{H}_{2}+\mathrm{CO}_{2}
\end{gathered}
$$

The three parts of this mechanism relevant to a reduced gravity discussion are 1) combustion of volatiles to create buoyant gas products and an environment that exceeds $800{ }^{\circ} \mathrm{C}, 2$ ) mass transport of steam and carbon dioxide through the porous char, and 3) mass transport of hydrogen and carbon monoxide away from the porous char. It is important to note that as pores in the char grow and combine, the pore structure deteriorates and transitions to fragments where convection between fragments becomes important, as depicted in Figure 1.

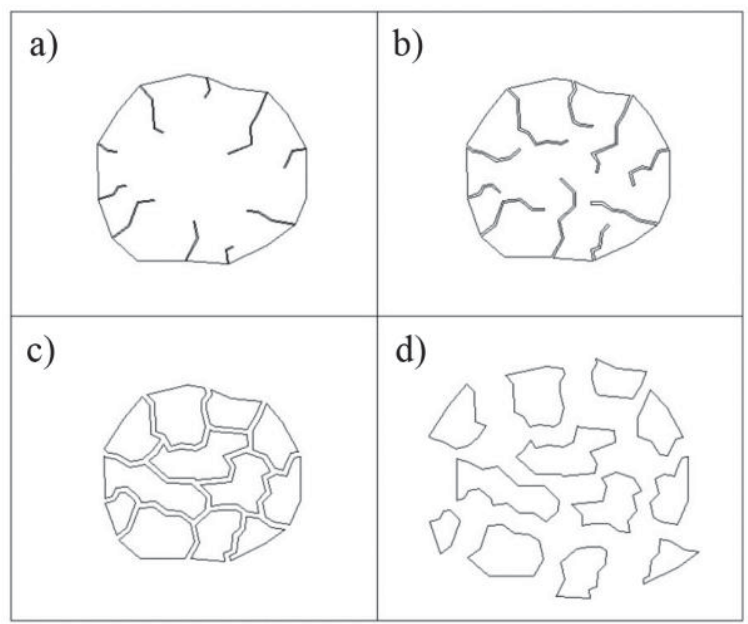

Fig. 1. Artist's rendition of a nascent char particle: a) with pores, b) with pores growing in depth and diameter, c) with pores becoming interconnected, and d) transitioning to fragments. 
To evaluate the problems and prospects of utilizing steam reforming as a source of fuel for in-space propulsion, and a means of reducing the volume of unsanitary waste, a research effort was initiated to model steam reforming and understand reduced gravity operations. Results from the modeling effort were utilized to design a potential reduced gravity aircraft experiment.

\section{Steam Reformer Modeling, a Multistep Process}

The premise for modeling is based on sequential decomposition of the organic material, first by volatilization of the light organics leaving char, and next by reaction of steam and carbon dioxide with the nascent char to produce hydrogen, carbon monoxide and carbon dioxide.

\section{A. Mass Transport in Char Pores - Early in the Process}

Additional research in the area has focused on the gasification of coal chars, where the coal char is modeled as either a porous solid or as a nonporous fragment. ${ }^{7}$ In a given porous particle, pores are considered to be small in diameter compared to the mean free path of a gas. One estimate of coal char pore diameter is $2 \mathrm{~nm}^{8}{ }^{8}$ Another estimate suggests pore diameters are on the order of 5 to $18 \mathrm{~nm} .{ }^{9}$ Based on an equation by Walker et.al, for most molecules a rough estimate of mean free path at 2 atmospheres is approximately $50 \mathrm{~nm},{ }^{10}$ so Knudsen diffusion is thought to dominate. In a char particle, a pore is analogous to a black body cavity where the carbon char serves as an isothermal structure and the pore itself serves as a cavity of high aspect ratio. In this analogy, the cavity is of uniform temperature and convection is absent, at least early in the steam reformer process, noteworthy to the reduced gravity discussion. The char particle is considered to have a network of pores, each pore branching into other pores. Particle deterioration ensues until a critical value is reached. As gaseous reactants diffuse in and consume the interior of the pores, the pores grow in depth and diameter. Fragmentation finally occurs. Upon deterioration, the grain remnants are separated, are at different temperatures, and under terrestrial conditions convection begins to play a dominant role. Here, diffusion and mass transport derived from convection serve to deliver reactants to and products away from the surface. It is the disintegration of particles and transition to convection which is of interest to the reduced gravity discussion.

\section{B. Networks, Critical Porosity, and Fragmentation - Late in the Process}

The network of pores and pore growth in solids is amply discussed in the literature. ${ }^{11}$ Pores inside a particle provide much surface area for gasification. Selected pores may be isolated initially from the outside, but are joined to the outside as an outside accessible pore grows and connects with the isolated region. Once the percolation threshold is surpassed, the connectivity of the pore structure increases substantially as pores join. Eventually, as much of the solid disappears via gasification, the remaining solid breaks into fragments. The process of fragmentation depends upon the degree of initial porosity, diffusion of the gaseous reactants, and the gasification kinetics on the interior surfaces, as well as mechanical forces such as stirring, mixing, or agitation. The creation of tens of fragments per char particle is not unreasonable. In any case, once particle disintegration occurs, the fragments are subject to dynamic conditions in the reactor. Convection begins playing a role, terrestrially.

For those fragments that are dense and without pores, gasification of the fragment particle follows the shrinking core model where gasification diminishes with diminishing accessible surface area. ${ }^{12}$

\section{Light Organics and the Impact of Buoyancy on Kinetics}

Finally, there is the step which creates the char in the first place, removal of the light organics. One concept for light organics combustion is a multiple orifice concept, as depicted in Figure 2, where multiple orifices in a cylinder introduce oxygenated steam into the reactor at the location where the organic material is to be consumed. The light organics volatilize rapidly via a heating mechanism where the oxygen mixed with the steam at a sufficiently high temperature causes an exothermic reaction, i.e combustion. The energy released is available to the system to heat the adjacent organic material, creating nascent char. Eventually, the volatiles are consumed by oxygen, char is consumed by the steam gasification and Bouduard reactions, and hydrogen, carbon monoxide, carbon dioxide and steam exit the system in thermochemical equilibrium. 


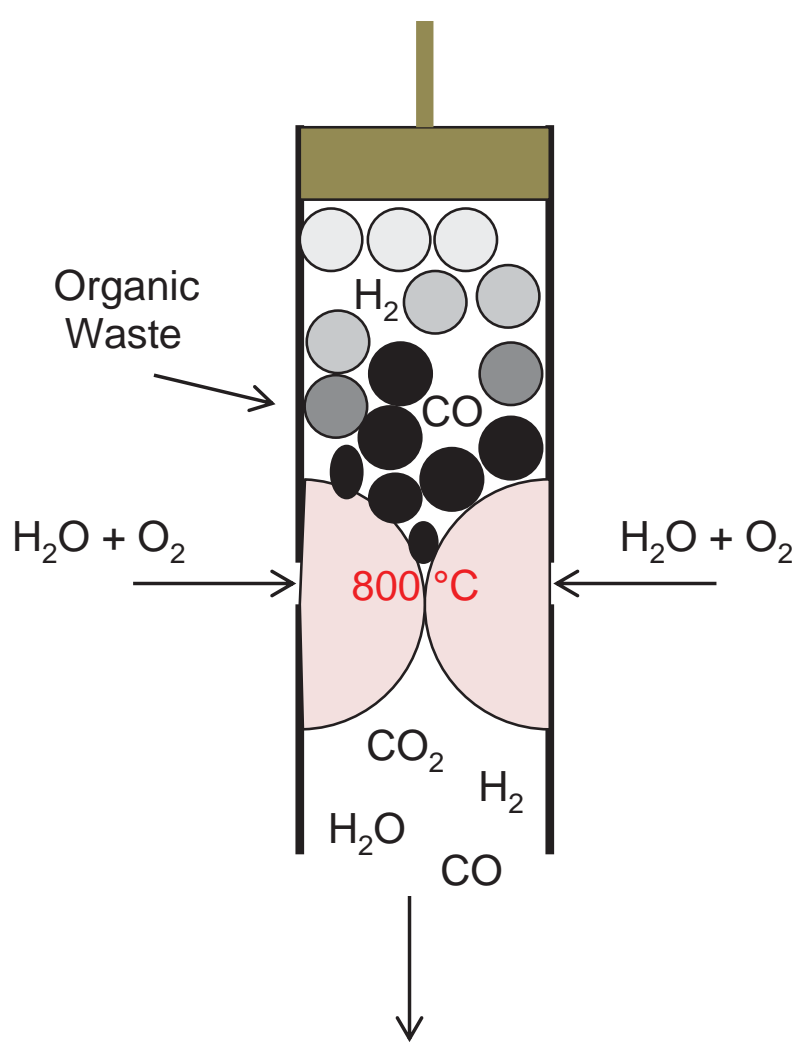

Fig. 2 Oxidation of light organics, creating nascent char (black).

The question of whether buoyancy plays an important role is answered by utilizing a Grashof number analysis, based on Equation 4, where $\mathrm{g}$ is the acceleration due to gravity, $\mathrm{m} \mathrm{s}^{-2}, \mathrm{l}$ is the characteristic dimension, $\xi$ is the coefficient of expansion of the fluid, $\mathrm{K}^{-1}, \Delta \mathrm{T}$ is the temperature difference between the surface and the bulk of the fluid, $\mathrm{K}$, and $v$ is the kinematic viscosity of the fluid, $\mathrm{m}^{2} \mathrm{~s}^{-1}$. Utilizing a representative dimension of one millimeter for spacing between remaining char particles, the coefficient of expansion and kinematic viscosity of steam (at an available value of $260^{\circ} \mathrm{C}$ ), and estimating the temperature difference between the surface and the bulk of the fluid to be of order $10^{\circ} \mathrm{C}$, the Grashof number is calculated to be much greater than 1 in 1 -g and much less than 1 in $10^{-6}$-g, suggesting that buoyancy is present in a terrestrial setting but would be absent in a microgravity setting. Forced convection in a microgravity setting would be needed to obtain performance comparable to that in 1-g.

$$
\mathrm{Gr}=\frac{g 1^{3} \xi \Delta \mathrm{T}}{\mathrm{v}^{2}}
$$

The result learned from this discussion is that there are two basic concerns when operating steam reforming in reduced gravity, the absence of buoyancy to heat and volatilize incoming organics introduced into the reaction zone, and the absence of convection late in the process that slows the mass transport for the steam gasification and Bouduard reactions. The former problem is likely solved through the use of forced convection. The latter problem is of concern in a reduced gravity setting and the prospects of utilizing steam reforming in a reduced gravity environment warrants further investigation in the form of a potential flight experiment.

\section{The Role of Added Oxygen and Steam Reforming in its Absence}

The next step in the discussion is the reaction kinetics of light volatiles combustion and the prospect of steam reforming in the absence of oxygen. The role of oxygen in the process is, in essence, to create an exothermic reaction to generate nascent char for subsequent steam gasification. ${ }^{6,13}$ Combustion occurs quickly compared to steam gasification, and the oxidation reactions are exothermic while the steam reforming reactions are endothermic. Operating without oxygen might be possible provided the $800{ }^{\circ} \mathrm{C}$ temperature regime can be 
achieved via means other than combustion. One concept, as shown in Figure 3, would be to introduce the waste as particles into a flowing stream of steam, perhaps with an inert carrier gas, and send the mixture to a cyclone reactor heated to $800{ }^{\circ} \mathrm{C}$. Adding thermal energy could be achieved by positioning the cyclone reactor at the focus of a solar concentrator. Such processing temperatures are reasonable from solar concentrators. ${ }^{14}$

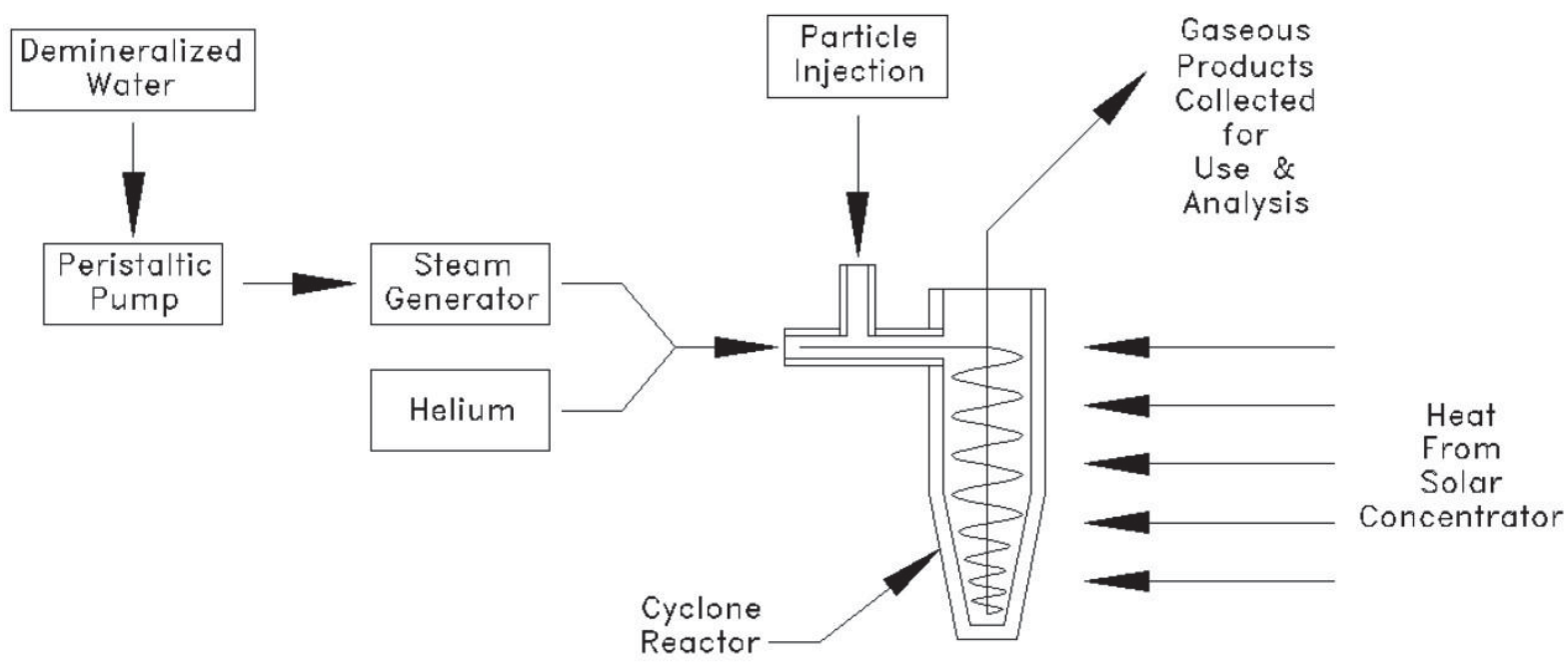

Fig. 3. Artist's rendition of a steam reformer incorporating a cyclone reactor at the focus of a solar concentrator.

Utilizing process heat from a solar concentrator has been proposed in the literature. ${ }^{15}$ As part of this study, the size of a solar concentrator sufficiently large to process $4 \mathrm{~kg}$ of trash per day (from a four person crew) and onsun for 24 hours a day was estimated and compared to other features of a deep space habitat. At Earth orbit, the

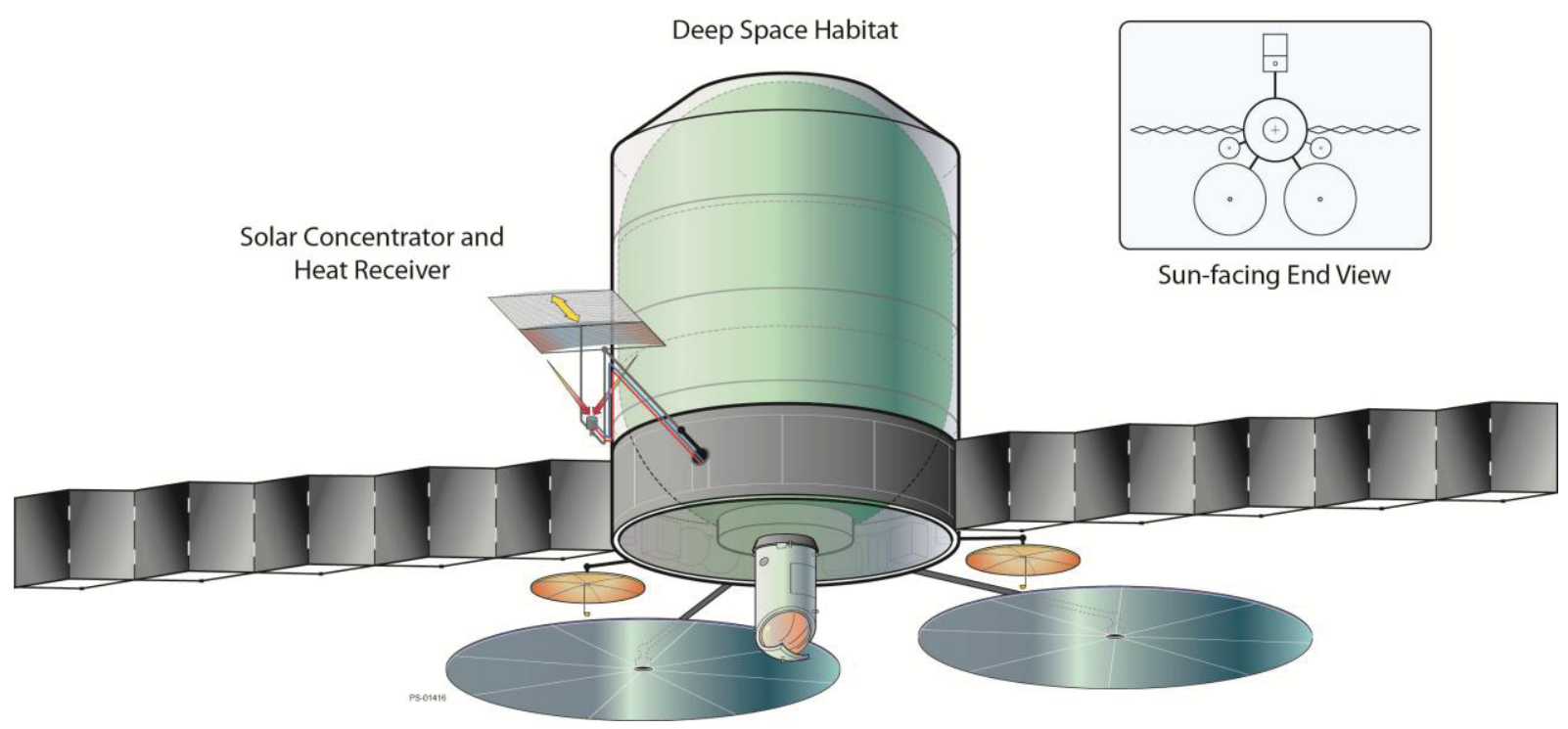

Fig. 4 Artist's rendition of a deep space habitat equipped with a solar concentrator and heat receiver to provide steam reformer process heat. 
area of concentrator needed was approximately $6 \mathrm{~m}^{2}$, expanding in transit to Mars to approximately $14 \mathrm{~m}^{2}$. An artist's rendition in Figure 4 shows that a Fresnel solar concentrator subsystem, deployed to the Mars setting, is slightly larger than the antennae of a deep space habitat yet smaller than the solar arrays and radiators.

\section{Reduced Gravity Flight Experiment}

Though the Logistics Reduction and Repurposing (LRR) project has selected steam reforming among many different competitive processes as the preferred method for repurposing waste into useful gases, an effort is needed to acquire crucial chemical kinetic data to transition to successful reduced gravity operations. A smallscale reactor specifically designed to fit within the requirements of an anticipated parabolic flight campaign (i.e. low-g duration, aircraft power availability, and safety) is needed to conduct such a flight experiment. The effort will identify whether the steam reformer process can be utilized in microgravity, determine the level of forced convection that would be needed for obtaining a performance comparable to that demonstrated terrestrially, and may provide guidance on an eventual design concept.

The specific objective of such an effort is to acquire kinetic data as a function of the concentration of oxygen in steam, temperature, and pressure and determine the dependence of reaction rate on these parameters using a model compound such as polyethylene which forms the majority of waste in a deep space mission. A reaction kinetics plot, as shown notionally in Figure 5, provides a means of illustrating the calculation of reaction rates from logarithmic mass loss as a function of temperature. Measuring mass loss presents two challenges, one in the absence of oxygenated steam where the polyethylene baseline mass loss due to evaporation needs to be evaluated in a non-reactive ambient gas and one in the presence of oxygenated steam where the polyethylene will be consumed. Utilizing a small quantity of polyethylene pre-melted into a droplet on a thin wire suspended in an inert atmosphere during heating, followed by the introduction of a slow flow of oxygenated steam at the desired temperature, is one concept. Accurate and precise mass measurements before and after reaction (and possibly during - via video image processing) should yield mass loss as a function of temperature, oxygen concentration in steam, and pressure (and time - via the video imaging).

The anticipated result of the effort is the demonstration of a single small-scale steam reformer yielding a reaction kinetics plot and steam reformer reaction rate data at various concentrations and pressures from a single model compound. Such intrinsic chemical kinetic information, i.e. pure kinetics in the absence of mass-transport limitations (by diffusion and/or convection) will lead to learning the minimum level of forced convection necessary in microgravity to eliminate transport limitations.

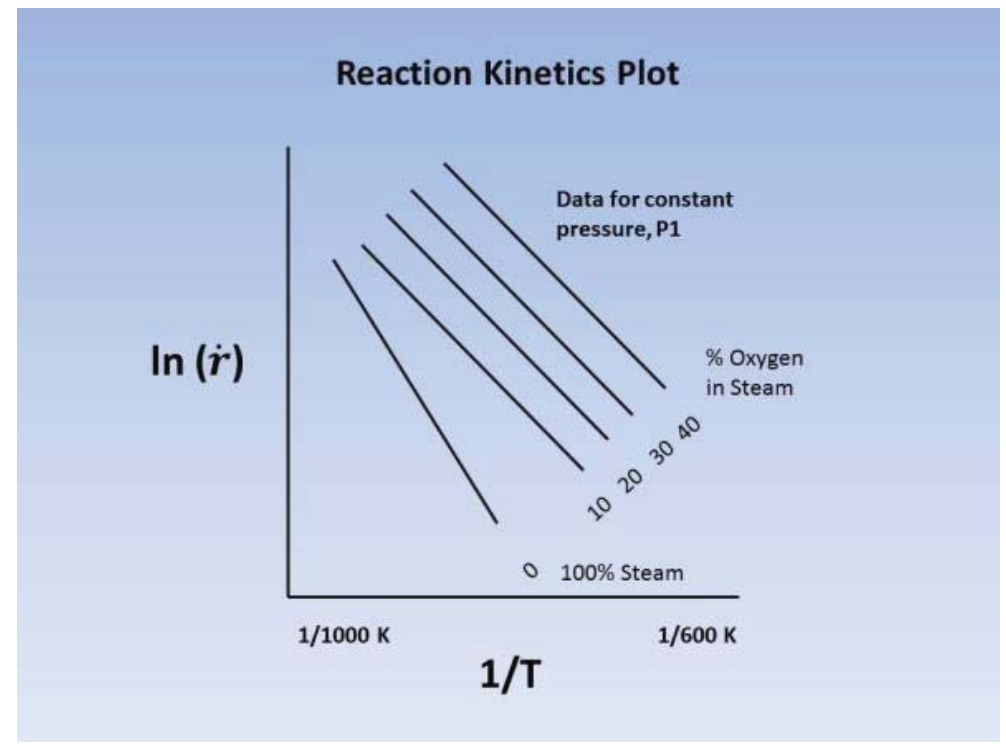

Figure 5. Mass loss vs. inverse temperature at various $\mathrm{O}_{2}$ concentrations and pressures.

\section{Future Work}

Steam reforming offers the prospect of reducing and repurposing waste materials into useful gases that could benefit propulsion and power. Potential future work in this area is two-fold: first, to understand the limitations 
imposed on the system via operation in a reduced gravity environment, and second, to mitigate the limitations through the use of forced convection. Operating in the absence of oxygen through the use of concentrated solar energy would be a considered an advantage.

\section{Conclusion}

This paper addresses the problems and prospects of utilizing steam reforming as a means of reducing the volume of waste materials generated by a four-person crew in a 400+ day deep space habitat mission, and in the process creating useful gases for propulsion and power. Steam reforming has been shown terrestrially to consume waste at a rate comparable to that needed by a four-person crew. Oxygenated steam creates an environment in a reactor where light organic volatiles are consumed by combustion enabling the remaining organics to form nascent char that is subsequently consumed by the steam gasification and Bouduard reactions. Buoyancy plays a role terrestrially in heating the organic waste prior to gasification. The gasification reactions are driven, in part, by mass transport through pores in the nascent char. The pores eventually grow together, as suggested by percolation theory, causing fragmentation of the char particles. A Grashof number analysis suggests that convection plays an important role terrestrially in heat and mass transport as the char particles and fragments are consumed, and that forced convection will be needed to operate a steam reforming reactor in a microgravity environment. The prospect of utilizing concentrated solar energy for providing the thermal environment is also considered. Finally, a next step is suggested where the kinetics of model compounds could be studied in a reduced gravity flight campaign to gather intrinsic chemical data to be used for subsequent concept design.

\section{Acknowledgments}

The authors gratefully acknowledge the Advanced Exploration Systems Program and the Logistics Reduction and Repurposing Project for their support of this effort. The authors also acknowledge Dr. Kurt R. Sacksteder, NASA Glenn Research Center, and Dr. Robert Zubrin, Pioneer Astronautics, for their many helpful discussions.

\section{References}

${ }^{1}$ Caraccio, A.J., Hintze, P., Anthony, S.M., Devor, R.M., Captain, J.G., and Muscatello, A.C., “Trash-to-Gas: Converting Space Trash into Useful Products," 43 ${ }^{\text {rd }}$ International Conference on Environmental Systems, Vail, CO, AIAA 2013-3440, July 2013.

${ }^{2}$ Linne, D.L., Palaszewski, B.A., Gokoglu, S.A., Balasubramaniam, B., Hegde, U.G., and Gallo, C., "Waste Management Options for Long-Duration Space Missions: When to Reject, Reuse, or Recycle," SciTech 2014, National Harbor, MD, AIAA 2014-0497, January 2014.

${ }^{3} \mathrm{Xu}, \mathrm{Q}$., Pang, S., and Levi, T., "Reaction kinetics and producer gas compositions of steam gasification of coal and biomass blend chars, part 1: Experimental investigation," Chemical Engineering Science, 66, pp. 2141-2148, 2011.

${ }^{4} \mathrm{Xu}, \mathrm{Q}$., Pang, S., and Levi, T., "Reaction kinetics and producer gas compositions of steam gasification of coal and biomass blend chars, part 2: Mathematical modelling and model validation," Chemical Engineering Science, 66, pp. 22322240, 2011.

${ }^{5}$ Franco, C., Pinto, F., Gulyurtlu, I., and Cabrita, I., "The study of reactions influencing the biomass steam gasification process," Fuel, 82, pp. 835-842, 2003.

${ }^{6}$ Berggren, M., Zubrin, R., Carrera, S., and Jonscher, P., "Lunar Organic Waste Reformer,” Space Resources Roundtable and Planetary \& Terrestrial Mining Sciences Symposium, Colorado School of Mines, June 2014.

${ }^{7}$ Mani, T., Mahinpey, N., and Murugan, P., "Reaction kinetics and mass transfer studies of biomass char gasification with $\mathrm{CO}_{2}$," Chemical Engineering Science, 66, pp. 36-41, 2011.

${ }^{8}$ Dombrowski, R.J., Hyduke, D.R., and Lastoskie, C.M., "Pore Size Analysis of Activated Carbons from Argon and Nitrogen Porosimetry Using Density Functional Theory,” Langmuir, 16, pp. 5041-5050, 2000.

${ }^{9}$ Everson, R.C., et.al., "Reaction kinetics of pulverized coal-chars derived from inertinite-rich coal discards: Gasification with carbon dioxide and steam," Fuel, 85, pp. 1076-1082, 2006.

${ }^{10}$ Chemistry and Physics of Carbon, Vol. 2., P.L. Walker, ed., Marcel Dekker, Inc., New York, NY, 1966, pp. $258-259$.

${ }^{11}$ Reyes, S., and Jensen, K. F., "Percolation Concepts in Modelling of Gas-Solid Reactions - I. Application to Char Gasification in the Kinetic Regime," Chemical Engineering Science, 41 (2), pp. 333-343, 1986.

12 Everson, R.C., Neomagus, H.W.J.P., Kasaini, H., and Njapha, D., "Reaction kinetics of pulverized coal-chars derived from inertinite-rich coal discards: Gasification with carbon dioxide and steam," Fuel, 85, pp. 1076-1082, 2006.

${ }^{13}$ Cormier, J.M., and Rusu, I., "Syngas production via methane steam reforming with oxygen: Plasma reactors versus chemical reactors,” J. Phys. D: Appl. Phys., 34, pp. 2798-2803, 2001.

14 Palaszewski, B.A., Hepp, A.F., Kulis, M.J., and Jaworske, D.A., “Aerospace Fuels from Nonpetroleum Raw Materials," 51 $1^{\text {st }}$ AIAA Aerospace Sciences Meeting, Grapevine, TX, AIAA 2013-0591, January 2013.

15 Crane, R., and Dustin, M.O., "Solar Dynamic Power/Process Heat Generation for the Proposed Lunar Oxygen Production Plant,” 1991 ASME International Solar Energy Conference, Reno, NV, March 1991. 